\title{
Penggunaan Media Kartu Berbahasa Indonesia-Mandarin Terhadap Pemahaman Materi Biologi Siswa Bilingual Di Pontianak
}

\section{Using Of Media Indonesian-Mandarin Card On Understanding Biological Material Of Bilingual Student In Pontianak}

\author{
Reni Marlina $^{1 *}$, Yokhebed ${ }^{1}$, Lily Thamrin ${ }^{2}$ \\ ${ }^{1}$ Program Studi Pendidikan Biologi, FKIP Universitas Tanjungpura, J1. Prof. Dr. Hadari Nawawi, Pontianak, Indonesia \\ ${ }^{2}$ Program Studi Pendidikan Bahasa Mandarin, FKIP Universitas Tanjungpura, Jl. Prof. Dr. Hadari Nawawi, Pontianak, \\ Indonesia \\ *Corresponding author: renitahak@yahoo.com
}

\begin{abstract}
Instructional media in the learning process not only as a tool but a messenger or learning information that must be in accordance with the student needs. In this study, researchers developed a media that integrates biology learning with Mandarin so that when students learn biology, also simultaneously recognize objects in biology and organizational level of life in Mandarin. Instructional media that will be made in the cards form contains about the object and scope of biology. The purpose of this study is to measure the effectiveness of Indonesianmandarin biology card on biology learning outcomes for secondary school. The method used is one shot case study. Research is done through the preparation, implementation, and data analysis. The results of the use media of Indonesian-mandarin card seen based on the average value of learning outcomes obtained test of $76.29 \%$ with mastery learning is in good criteria. Thus it can be concluded that the use of Indonesian-mandarin card can be one strategy to improve student learning outcomes in biology learning.
\end{abstract}

Keywords: media, biology card, material understanding

\section{PENDAHULUAN}

Mutu pendidikan di Indonesia masih belum membanggakan. Terdapat beberapa faktor yang mempengaruhi rendahnya mutu pendidikan antara lain kualitas proses belajar mengajar yang masih belum dapat menciptakan pembelajaran yang berkualitas, masih rendahnya profesionalisme guru, hal ini terutama disebabkan oleh proses persiapan pembelajaran yang dilakukan oleh guru berorientasi hanya pada bagaimana siswa dapat menguasai materi yang disampaikan, sehingga menyebabkan siswa belajar dengan menghafal. Proses menghapal menyebabkan kemampuan siswa dalam belajar tidak dapat berkembang secara maksimal.

Agar dapat meningkatkan mutu pembelajaran biologi yang disenangi siswa, bermakna dan menghidari dari hapalan, maka guru dituntut untuk dapat melakukan perencanaan dengan baik dari tiap pembelajaran yang akan dilakukannya. Menurut Syaefudin \& Syamsudin (2007), pengertian perencanaan secara umum hanya dapat mengacu kepada persiapan internal yang dilakukan oleh guru secara kelompok atau secara individu. Agar hasil belajar meningkat dan semakin berkuallitas, maka diperlukan beberapa kreatifitas dari seorang pengajar dimana guru sebagai fasilitator dapat menggunakan media yang sesuai dengan materi dan tujuan pembelajaran yang ingin dicapai. Media menurut Hanafiah \& Suhana (2012) merupakan segala bentuk perangsang yang dapat berupa alat yang disediakan oleh guru yang bertujuan untuk mendorong siswa agar dapat termotivasi dalam belajar secara cepat dan tepat, mudah digunakan, sesuai dengan umur siswa, dan dapat menghidari terjadinya verbalisme. Media pembelajaran adalah alat bantu dalam proses mendengar dan melihat materi pembelajaran yang digunakan oleh siswa dalam rangka memperoleh pengalaman belajar yang menyenangkan dan bermakna (Zaenal, 2003). Menurut Arsyad (2011), pengertian media adalah suatu perantara atau pengantar pesan dari pengirim kepada penerima pesan. Pengertian lain dari media dapat berupa manusia, materi ajar, atau suatu kejadian yang dapat membangun suatu kondisi yang membuat siswa dapat memperoleh hasil belajar seperti pengetahuan, keterampilan atau sikap. Berdasarkan pengertian ini guru, buku teks dan lingkungan sekolah siswa dapat dikaakan sebagai media.

Salah satu media yang sering digunakan oleh guru biologi adalah media kartu bergambar. Menurut Susilana \& Riyana (2008) terdapat beberapa manfaat dari media pembelajaran, diantaranya adalah dapat memperjelas pesan agar tidak terlalu verbalistis, dapat 
mengatasi keterbatasan daya indera, dapat menimbulkan semangat untuk belajar, dan memungkinkan siswa belajar secara mandiri sesuai dengan bakat dan kemampuan yang dimilikinya.

Sebagian besar materi biologi tidak dapat diajarkan hanya dengan metode ceramah. Diperlukan suatu media untuk melibatkan siswa dalam proses belajar mengajar (Bonwell \& Eison, 1991) pentingnya media pembelajaran dalam proses belajar mengajar diungkapkan oleh Klemm \& Tuthill (2003) salah satunya untuk memusatkan perhatian siswa dalam belajar dan menghindari siswa dari lamunan. Penggunaan media pembelajaran juga diharapkan dapat meningkatkan pemahaman siswa terkait dengan materi yang diajarkan. Sejauh ini, kendala yang dihadapi dalam penggunaan media dalam pembelajaran biologi masih digambarkan dalam bentuk peralatan yang canggih dan mahal. Yang terpenting adalah dalam merancang media pembelajaran, harus disesuaikan dengan fasilitas yang dimiliki sekolah, karena tidak semua media dapat digunakan di semua sekolah contohnya media yang berbasis ICT. Namun bukan berarti sekolah yang memiliki fasilitas kurang memadai tidak dapat menggunakan media pembelajaran (Wilson, 2014), karena pada kenyataannya, terdapat media yang sederhana namun dapat meningkatkan motivasi siswa dalam belajar, salah satunya adalah media kartu (Fajriyah \& Churiyah, 2016).

Media kartu merupakan potongan-potongan kertas yang berukuran $12,5 \times 15 \mathrm{~cm}$ yang berisi materi biologi tentang objek dan ruang lingkup biologi. Satu sisi bertuliskan bahasa mandarin dan sisi lainnya dalam bahasa Indonesia. Pada pembelajaran menggunakan kartu ini setiap siswa secara berpasangan saling tanya jawab tentang isi kartu.

Media yang dibuat tersebut, mengintegrasikan pembelajaran biologi dengan bahasa mandarin sehingga pada saat siswa belajar biologi siswa juga secara bersamaan mengenal objek-objek dalam biologi dan tingkat organisasi kehidupan dalam bahasa mandarin. Media pembelajaran yang akan dibuat dalam bentuk kartu berisi tentang objek dan ruang lingkup biologi. Media kartu biologi yang dirancang dengan bahasa indonesia dan mandarin ini selain dapat digunakan dalam pembelajaran biologi di sekolah menengah juga dapat digunakan dalam pelajaran bahasa mandarin. Hal ini sesuai dengan ruang lingkup pada pelajaran bahasa mandarin salah satunya yaitu keterampilan mendengarkan, berbicara, membaca, dan menulis terkait kehidupan sehari hari dan identitas diri yang terkait dengan objek biologi dan tingkat organisasi kehidupan. Selain itu kompetensi yang dituntut dalam pelajaran bahasa mandarin juga terkait kemampuan berkomunikasi interpersonal, transaksional, dan fungsional, hal ini dapat difasilitasi dengan media kartu biologi yang dirancang dengan aksara Tionghoa (hanzi), romansia (pinyin) dan nada. Menurut Susilana \& Riyana (2008) media kartu memliliki kelebihan yaitu mudah dibawa kemana-mana, praktis, gampang diingat dan menyenangkan.Penelitian ini didukung oleh hasil penelitian Ariadi (2017) yang mengembangkan edugame pengenalan anggota tubuh manusia menggunakan tiga bahasa yaitu indonseia, inggis dan jawa, edugame ini dapat menciptakan pembelajaran yang interaktif dan menyenangkan sehingga menarik minat siswa untuk mempelajari anggota tubuh manusia dan mempelajari bahasa. Sedangkan hasil penelitian Rahmatin \& Khabibah (2016) media permainan kartu Umath sangat efektif dalam pembelajaran matematika memiliki respon yang positif dan siswa yang tuntas sebesar $87,76 \%$ Dengan demikian peneliti tertarik untuk menggunakan media kartu biologi berbahasa Indonesia-mandarin untuk mengukur hasil belajar siswa sekolah menengah.

Pada bahasa Mandarin terdapat 3 hal yang harus dipelajari selain mengartikannya. Tiga hal tersebut terdiri dari; aksara Tionghoa (hanzi), romansia (pinyin) dan nada. Pinyin dan nada memiliki satu kesatuan. Berdasarkan Peraturan Menteri Pendidikan Dan Kebudayaan Republik Indonesia Nomor 21 Tahun 2016 Tentang Standar Isi Pendidikan Dasar dan Menengah Keterampilan berbahasa mandarin untuk sekolah menengah meliputi keterampilan berkomunikasi interpersonal, transaksional, dan fungsional dengan ruang lingkup salah satunya keterampilan mendengarkan, berbicara, membaca, dan menulis terkait kehidupan sehari hari (日常生活 rìcháng shēnghuó) dan identitas diri 个人信息 gèrén xìnxī), yang terkait dengan objek biologi dan tingkat organisasi kehidupan. Berdasarkan Silabus Kurikulum 2013 Peminatan Bahasa Mandarin terdapat kegiatan pembelajaran mengomunikasikan melalui tindakan memberi dan meminta informasi terkait perbandingan jumlah dan sifat orang, binatang, benda serta meresponnya dengan memperhatikan fungsi sosial, struktur teks, dan unsur kebahasaannya yang sesuai dengan konteks. Dengan demikian, melalui penggunaan media kartu berbahasa indonesaimandarin, ketiga aspek dalam kemampuan berbahasa mandarin dapat diukur.

\section{METODE PENELITIAN}

Desain yang digunakan dalam penelitian ini adalah one shot case study. Desain One shot case study ini digunakan dimana dalam penelitian ini terdapat suatu kelompok yang diberi perlakuan dan selanjutnya diobservasi hasilnya (Juni \& Afiah, 2014).

Prosedur penelitian ini dilakukan melalui 2 tahap yaitu tahap perencanaan dan tahap pelaksanaan. Tahap perencanaan adalah sebagai berikut:

a. Penyusunan Tes (criterion-test construction)

b. Pemilihan Format (format selection)

Pemilihan format dalam pengembangan dimaksudkan dengan mendesain isi pembelajaran, pemilihan pendekatan, dan sumber belajar, mengorganisasikan dan merancang isi media kartu biologi berbahasa indonesiamandarin, membuat desain kartu. yang meliputi desain layout, gambar, dan tulisan.

c. Tahap mendesain/ merancang (initial design)

Desain dilakukan dengan merancang media kartu sesuai dengan desainnya yaiu dengan 
ukuran kartu 12,5 x $15 \mathrm{~cm}$, mendesain layout-nya, menyesuaikan gambar sesuai dengan objek biologi dan organisasi kehidupan, memberikan tulisan pada gambar baik bahasa Indonesia, bahasa mandarin (aksara, pinyin, dan nada). Media kartu dirancang dengan aplikasi corel draw dan dicetak menggunakan paper glossy.

Pada tahap pelaksanaan dilakukan hal-hal sebagai berikut:

a. Validasi Ahli (expert judgement)

Validasi ahli ini berfungsi untuk memvalidasi isi materi biologi dan bahasa mandarin dalam media kartu sebelum dilakukan uji coba. Media kartu yang telah disusun kemudian divalidasi oleh ahli materi dalam bidang biologi dan bahasa mandarin masing-masing 3 orang serta oleh ahli media berjumlah 3 orang, sehingga dapat diketahui apakah media kartu tersebut layak diterapkan atau tidak. Validator berasal dari ahli yang terdiri dari guru dan dosen pada bidang biologi, bahasa mandarin dan media pembelajaran.Hasil dari validasi ini digunakan sebagai bahan perbaikan media kartu yang dikembangkan.

b. Uji Coba Produk (development testing)

Setelah dilakukan validasi ahli kemudian dilakukan uji coba lapangan terbatas untuk mengetahui hasil penerapan media kartu dalam pembelajaran di kelas, meliputi pengukuran hasil belajar dan keterampilan berbahasa mandarin. Hasil yang diperoleh dari tahap ini berupa media kartu yang telah direvisi.

Penelitian ini melibatkan subjek yaitu siswa kelas VIII SMP Immanuel Pontianak. Instrumen yang digunakan berupa tes hasil belajar. Tes dilakukan untuk melihat kemampuan siswa dalam memahami konsep biologi dan bahasa mandarin.Soal tes berbentuk pilihan ganda berjumlah masing-masing 20 soal.Sebelum digunakan soal tes divalidasi terlebih dahulu oleh validator sekaligus validasi ahli materi. Analisis tes hasil belajar dilakukan dengan tahapan sebagai berikut:

a. Penskoran

Setiap jawaban benar diberi skor 1 dan jawaban salah diberi skor 0 . Nilai individual diperoleh menggunakan rumus:

$\mathrm{S}=\frac{\mathrm{R}}{\mathrm{N}} \times 100(1)$

Keterangan:

$\mathrm{S}=$ nilai yang dicari

$\mathrm{R}=$ Skor yang diperoleh

$\mathrm{N}=$ Skor maksimum dari tes

$100=$ bilangan tetap

(Purwanto, 2008)

b. Penilaian

Pada tahap penilaian dilakukan dengan memberikan kategori berdasarkan nilai yang diperoleh tiap siswa dengan mengacu pada kriteria yang ditampilkan pada Tabel 1.
Tabel 1. Predikat dan Kategori Nilai

\begin{tabular}{ccc}
\hline Rentang Nilai & Predikat & Kategori \\
\hline $86-100$ & A & Sangat Baik \\
$81-85$ & A- & \\
$76-80$ & B+ & \\
$71-75$ & B & Baik \\
$66-70$ & B- & \\
$61-65$ & C+ & \\
$56-60$ & C & Cukup \\
$51-55$ & C- & \\
$46-50$ & D+ & Kurang \\
$0-45$ & D & \\
\hline
\end{tabular}

(Kemendikbud, 2013)

c. Nilai rata-rata hasil belajar diperoleh dengan menggunakan rumus:

$$
\overline{\mathrm{X}}=\frac{\sum \mathrm{x}}{\mathrm{N}}
$$

\section{Keterangan}

$\overline{\mathrm{x}}=$ Nilai rata-rata yang dicari

$\sum \mathrm{x}=$ Jumlah nilai

$\mathrm{N}=$ Aspek yang dinilai

(Sudjana, 2010).

d. Nilai klasikal

$\mathrm{P}=\frac{\sum \text { siswa yang tuntas belajar }}{\sum \text { siswa }} \times 100 \%$

Tabel 2. Kriteria Tingkat Keberhasilan Siswa

\begin{tabular}{lll}
\hline No & $\begin{array}{l}\text { Tingkat } \\
\text { Keberhasilan }\end{array}$ & Keterangan \\
\hline 1 & $86-100$ & Sangat Tinggi \\
2 & $71-85$ & Tinggi \\
3 & $56-70$ & Sedang \\
4 & $41-55$ & Rendah \\
5 & $26-40$ & Sangat Rendah \\
\hline
\end{tabular}

(Aqib, dkk., 2009)

\section{HASIL DAN PEMBAHASAN}

\section{Skor Tes Hasil Belajar Siswa}

Tes hasil belajar yang diberikan terdiri dari delapan (8) indikator yaitu sebagai berikut:

Indikator $1=$ Bakteri

Indikator 2 = Jaringan pada manusia

Indikator 3 = Organ dan fungsi organ pada manusia

Indikator $4=$ Mekanisme sistem organ pada manusia

Indikator $5=$ Tumbuhan

Indikator $6=$ Hewan

Indikator $7=$ Jamur

Indikator $8=$ Protista

Pada indikator bakteri diperoleh hasil sebesar 40.7\% siswa dapat menjawab dengan benar atau sebanyak 11 siswa dari 27 siswa dapat menjawab dengan tepat. Konsep bakteri kurang dipahami siswa. Hal ini disebabkan konsep ini bersifat abstrak. Media kartu berbahasa Indonesia-mandarin belum cukup 
menggambarkan ciri khas dari bakteri dan bagianbagian dari bakteri. Seperti yang dinyatakan oleh Hidayatussaadah, Hidayati, \& Umniyatie (2016) bahwa konsep ciri khas dan klasifikasi bakteri berdasarkan jumlah dan letak flagela dinyatakan paling sulit dipelajari oleh siswa dibanding mengidentifikasi contoh. Hal ini disebabkan karena pada materi klasifikasi bakteri yang diidentifikasi berdasarkan perbedaan jumlah dan letak flagela terdapat banyak istilah dalam bahsa latin yang digunakan seperti amfitrik, lofotrik, monotrik, dan peritrik. Karena banyaknya istilah inilah membuat siswa siswa mengalami kesulitan dalam memahaminya.

Pada indikator jaringan pada manusia diperoleh persentase jawaban siswa seperti tercantum pada Tabel 3 di bawah ini.

Tabel 3. Jumlah Jawaban Benar dan Persentase Pemahaman Konsep Jaringan Pada Manusia

\begin{tabular}{ccc}
\hline Item Soal & $\begin{array}{c}\text { Jumlah jawaban } \\
\text { benar }(\mathrm{n}=27)\end{array}$ & Persentase (\%) \\
\hline 6 & 24 & 88.9 \\
7 & 27 & 100 \\
\hline \multicolumn{3}{c}{ Rata-rata } \\
\hline
\end{tabular}

Keterangan item:

6. Menentukan jenis otot jantung

7. Mengidentifikasi ciri otot lurik

Pemahaman siswa pada konsep organ dan fungsi organ pada manusia tersebar dalam 6 item soal seperti yang tercantum pada Tabel 4 di bawah ini.

Tabel 4. Jumlah Jawaban Benar dan Persentase

Pemahaman Konsep Organ dan Fungsi organ Pada Manusia

\begin{tabular}{ccc}
\hline Item Soal & $\begin{array}{c}\text { Jumlah jawaban } \\
\text { benar }(\mathrm{n}=27)\end{array}$ & Persentase (\%) \\
\hline 1 & 25 & 92.59 \\
2 & 26 & 96.3 \\
5 & 26 & 96.3 \\
8 & 23 & 85.19 \\
9 & 25 & 92.59 \\
10 & 7 & 25.93 \\
\hline \multicolumn{3}{c}{ Rata-rata } \\
\hline
\end{tabular}

Keterangan item:

1. Menunjukkan organ ginjal manusia

2. Mengidentifikasi organ awal system pencernaan manusia

5. Menjelaskan fungsi alat pendengaran manusia

8. Menentukan letak bagian dermis pada kulit manusia

9. Menjelaskan fungsi lapisan epidermis pada kulit manusia

10. Menentukan letak lapisan adipose pada kulit manusia

Pemahaman siswa terhadap konsep sistem organ ditampilkan pada Tabel 5 di bawah ini.
Tabel 5. Jumlah Jawaban Benar dan Persentase Pemahaman Konsep Sistem Organ

\begin{tabular}{ccc}
\hline Item Soal & $\begin{array}{c}\text { Jumlah jawaban } \\
\text { benar }(\mathrm{n}=27)\end{array}$ & Persentase (\%) \\
\hline 3 & 26 & 96.3 \\
4 & 27 & 100 \\
\hline & Rata-rata & 98.15 \\
\hline
\end{tabular}

Keterangan item:

3. menjelaskan pengertian saluran pernapasan

4. Mengidentifikasi sistem pencernaan

Dari 27 siswa, hanya 1 siswa yang salah dalam menjawab pertanyaan mengenai pengertian saluran pernapasan. Materi sistem pernapasan merupakan salah satu materi yang dianggap mudah bagi siswa. Miskonsepsi yang dialami oleh 1 siswa ini disebabkan karena adanya anggapan respirasi dan pernapasan merupakan suatu proses yang sama. Kesalahpahaman yang umum ditemukan ditiap siswa dalam pembelajaran biologi adalah respirasi dan pernapasan yang dianggap sebagai suatu proses yang sama. Namun, sebenarnya istilah respirasi mengacu pada metabolisme sel dan istilah pernapasan lebih pada proses menghirup dan menghembuskan udara. Siswa mungkin mendengar bahwa paru-paru kita adalah bagian dari sistem pernapasan, yang dapat menambah kebingungan dari istilah-istilah ini. Selain itu, gagasan respirasi seluler cukup sulit untuk dipahami siswa karena mereka tidak dapat melihatnya terjadi (Barrass, 1984).

Pemahaman siswa terhadap konsep tumbuhan ditampilkan pada Tabel 6 di bawah ini.

Tabel 6. Jumlah Jawaban Benar dan Persentase Pemahaman Konsep Tumbuhan

\begin{tabular}{|c|c|c|}
\hline Item Soal & $\begin{array}{c}\text { Jumlah jawaban } \\
\text { benar }(n=27)\end{array}$ & Persentase (\%) \\
\hline 11 & 21 & 77.8 \\
\hline 12 & 17 & 63 \\
\hline 18 & 12 & 44.4 \\
\hline \multicolumn{2}{|c|}{ Rata-rata } & 61.73 \\
\hline
\end{tabular}

Keterangan item:

11. Menentukan ciri umum tumbuhan dikotil

12. Mengidentifikasi tumbuhan berkambium

18. Menentukan contoh gymnospermae

Permasalahan yang dihadapi siswa dalam menjawab pertanyaan tentang tumbuhan salah satunya adalah dalam menentukan contoh tumbuhan yang tergolong ke dalam gymnospermae. Menurut Zarisma, Qurbaniah, \& Muldayanti (2016) permasalahan ini disebabkan karena kesalahan siswa dalam mengidentifikasi ciri yang dimiliki oleh tumbuhan gymnospermae. 15 siswa dari 27 siswa menganggap angiospermae. Padahal ciri yang dilihat adalah batang bercabang, berakar tunggang, berdaun, berbiji dan 
terdapat strobilus. Ciri tersebut dimiliki oleh tumbuhan gymnospermae.

Pemahaman siswa terhadap konsep hewan ditampilkan pada Tabel 7 di bawah ini.

Tabel 7. Jumlah Jawaban Benar dan Persentase Pemahaman Konsep Hewan

\begin{tabular}{ccc}
\hline Item Soal & $\begin{array}{c}\text { Jumlah jawaban } \\
\text { benar }(\mathrm{n}=27)\end{array}$ & Persentase (\%) \\
\hline 16 & 23 & 85.2 \\
17 & 26 & 96.3 \\
\hline \multicolumn{3}{c}{ Rata-rata } \\
\hline
\end{tabular}

Keterangan item:

16. Menentukan contoh hewan vertebrata

17. Mendeskripsikan ciri mamalia

Pada materi tentang hewan khususnya tentang mamalia, hanya 1 siswa yang mengalami kesulitan. Kesulitan dalam mendeskripsikan ciri mamalia ini dikarenakan kurang mengamati dan memahami isi kartu tentang mamalia. Penggunaan media dalam mempelajari klasifikasi makhluk hidup sangat diburtuhkan, seperti yang diungkapkan oleh Hermaya, Miladiansyah, \& Angreni (tanpa tahun) bahwa pokok bahasan tentang klasifikasi makhluk hidup terutama tentang taksonomi hewan mamalia vertebrata dalam proses pembelajarannya secara teori akan menyebabkan siswa mengalami kesulitan dalam

memahaminya. Oleh karena itu, diperlukan sebuah media yang dapat membantu siswa untuk belajar biologi terutama tentang taksonomi hewan mamalia vertebrata agar menjadi lebih mudah.

Pemahaman siswa terhadap konsep jamur ditampilkan pada Tabel 8 di bawah ini.

Tabel 8. Jumlah Jawaban Benar dan Persentase Pemahaman Konsep Jamur

\begin{tabular}{ccc}
\hline Item Soal & $\begin{array}{c}\text { Jumlah jawaban } \\
\text { benar }(\mathrm{n}=27)\end{array}$ & Persentase (\%) \\
\hline 15 & 4 & 14.8 \\
19 & 13 & 48.1 \\
\hline & Rata-rata & 31.45 \\
\hline
\end{tabular}

Keterangan item:

15. Mendeskripsikan fungsi jamur zygomycota

19. Menentukan contoh jamur Ascomycota

Pembahasan tentang materi jamur khususnya tentang jenis-jenis dan contoh jamur serta pengelompokkannya dapat menjadi satu materi yang rumit dan sulit dimengerti. Apalagi mengenai siklus hidup jamur bisa sangat rumit dan sulit dimengerti. Misalnya tentang transformasi plasmodium menjadi sejumlah besar tubuh buah di myxomycetes atau dikaryotik dari hifa monokariotik pada jamur (Klees \& Piepenbring, 2017).

Pada soal tentang menentukan contoh jamur Ascomycota terdapat 14 siswa yang tidak menjawab dengan benar. Hal ini disebabkan siswa kurang mengidentifikasi adanya ascocarp yang merupakan salah satu ciri khas yang dimiliki oleh jamur pada divisi ascomycota. Hal ini sesuai dengan hasil penelitian Amerudin, Ariyati, \& Mardiyaningsih (2013) yang menyatakan bahwa pada konsep tentang penentuan contoh jenis jamur dinyatakan sebanyak $35.13 \%$ siswa yang kurang teliti dalam memperhatikan ascorcap yang merupakan ciri khas yang dimilki oleh divisi ascomycota. Salah satu penyebabnya adalah siswa masih belum bisa membedakan ciri khas pada masing-masing divisi jamur berdasarkan pada siklus hidupnya.

Pemahaman siswa terhadap konsep protista ditampilkan pada Tabel 9 di bawah ini.

Tabel 9. Jumlah Jawaban Benar dan Persentase Pemahaman Konsep Protista

\begin{tabular}{ccc}
\hline Item Soal & $\begin{array}{c}\text { Jumlah jawaban } \\
\text { benar }(\mathrm{n}=27)\end{array}$ & Persentase (\%) \\
\hline 14 & 19 & 70.4 \\
20 & 20 & 74.1 \\
\hline \multicolumn{3}{c}{ Rata-rata } \\
\hline
\end{tabular}

Keterangan item:

14. Protista mirip tumbuhan

20. Pengertian protozoa

Pemahaman siswa dalam materi protista khususnya pada protista mirip tumbuhan dan pengertian protozoa dapat dikategorikan baik, karena masing-masing hanya 8 dan 7 siswa dari 27 siswa yang mengalami kesalahan dalam menjawab soal tes. Kesalahan ini disebabkan karena siswa hanya menghapal konsep tanpa dapat menghubungkan dengan pengetahuan awal yang telah diperolehnya. Hal ini sesuai dengan hasil penelitian yang diperoleh Zunitasari, Hidayati, \& Triatmanto (2016), yang menyatakan bahwa berdasarkan tes protista yang digunakan untuk mengukur pemahaman siswa terhadap materi protista diperoleh hasil siswa masih belum mampu menghubungkan informasi baru yang baru dipelajari dengan pengetahuan yang telah dimiliki sebelumnya sehingga yang terjadi adalah pola belajar mereka bersifat hafalan. Karena siswa belajar dengan menghapal, akibatnya siswa merasa kesulitan dalam mengingat materi pelajaran atau lupa. Menurut Khodijah (2014) lupa (forgetting) merupakan hilangnya kemampuan dalam mengingat atau memunculkan kembali sesuatu hal yang telah dipelajari sebelumnya.

Penggunaan kartu berbahasa Indonesiamandarin dalam penelitian ini bertujuan untuk menghindarkan siswa menghapal materi ajar. Karena dalam kartu yang telah didesain, ditonjolkan gambargambar materi yang bersifat abstrak. Selain itu, dalam penggunaannya pada proses belajar mengajar, siswa dituntut untuk berkelompok atau minimal berpasangan sehingga dapat melakukan tanya jawab dengan pertanyaan yang dikarang oleh teman kelompok karena dalam kartu tidak ditampilkan 
pertanyaan. Dengan demikian, pemahaman siswa terhadap materi akan semakin baik dan lebih bermakna.

Menurut pendapat Ausubel \& Novak, materi pelajaran yang baru dipelajari secara bermakna akan lebih lama diingat (Mulyati, 2005). Hal-hal yang sifatnya dihapal akan lebih mudah dilupakan dibandingkan hasil dari proses praktik-praktik pengalaman belajar (meaningful) sedangkan sesuatu yang kurang berarti (less meaningfull) akan lebih mudah dilupakan (Makmun, 2004).

\section{Predikat dan Kategori Hasil Belajar Siswa}

Pemahaman materi biologi khususnya pada aspek objek biologi dan ruang lingkup biologi diukur kepada satu kelas yang berjumlah 27 siswa yaitu kelas VIII bilingual Immanuael Pontianak. Pelaksanaan tes dilakukan setelah siswa memperoleh pembelajaran dengan menerapkan media kartu berbahasa Indonesia -Mandarin yang diajar oleh guru biologi dan diobservasi oleh 2 orang dosen yang berasal dari program studi pendidikan biologi FKIP Universitas Tanjungpura Pontianak. Predikat dan kategori hasil belajar tiap siswa ditampilkan pada Tabel 10 di bawah ini.

Tabel 10. Predikat dan Kategori Hasil Belajar Tiap Siswa

\begin{tabular}{ccccc}
\hline $\begin{array}{c}\text { Kode } \\
\text { Siswa }\end{array}$ & $\begin{array}{c}\text { Skor } \\
\text { Siswa }\end{array}$ & $\begin{array}{c}\text { Persentase } \\
(\%)\end{array}$ & Predikat & Kategori \\
\hline Hos & 16 & 80 & B+ & Baik \\
And & 15 & 75 & B & Baik \\
Jas & 12 & 60 & C & Cukup \\
Irv & 16 & 80 & B+ & Baik \\
Sta & 16 & 80 & B+ & Baik \\
Rio & 13 & 65 & C+ & Cukup \\
Far & 17 & 85 & A- & Sangat \\
Cha & 15 & 75 & Baik & Baik \\
Bir & 17 & 85 & A- & Sangat \\
Vio & 16 & 80 & Baik \\
Gle & 18 & 90 & A & Baik \\
& & & & Sangat \\
Gil & 17 & 85 & Baik & Sangat \\
Que & 15 & 75 & B & Baik \\
Car & 18 & 90 & A & Sangat \\
& & & & Baik \\
Yoa & 18 & 90 & A & Sangat \\
& & & & Baik \\
Cel & 18 & 90 & A & Sangat \\
& & & & Baik \\
Eve & 17 & 85 & A- & Sangat \\
Gra & 11 & 55 & C- & Cukup \\
Rya & 11 & 55 & C- & Cukup \\
Nat & 16 & 80 & Baik \\
Dav & 15 & 75 & B & Baik
\end{tabular}

\begin{tabular}{ccccc} 
Put & 11 & 55 & C- & Cukup \\
Bil & 13 & 65 & C+ & Cukup \\
Geo & 14 & 70 & B- & Baik \\
Alf & 13 & 65 & C+ & Cukup \\
Jon & 18 & 90 & A & Sangat \\
& & & Baik \\
Hos & 16 & 80 & B + & Baik \\
\hline \multicolumn{2}{r}{ Rata-rata } & $\mathbf{7 6 . 2 9}$ & \multicolumn{2}{c}{ Baik } \\
\hline
\end{tabular}

\section{Kriteria Tingkat Keberhasilan Siswa}

Kriteria tingkat keberhasilan siswa ditampilkan pada

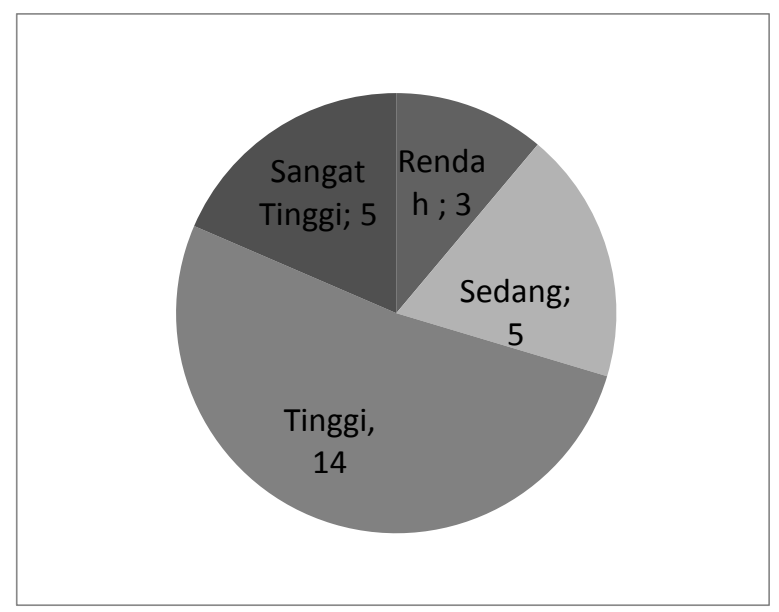

Gambar 1 di bawah ini.

Gambar 1. Jumlah Siswa dalam Tiap Kategori

Tingkat keberhasilan siswa dikategorikan ke dalam 4 kriteria yaitu sangat tinggi, tinggi, sedang, dan rendah. Terdapat 5 orang yang dikategorikan ke dalam kriteria sangat tinggi, 14 orang dengan kriteria tinggi, 5 orang dalam kategori sedang dan 3 orang dalam kategori rendah.

\section{SIMPULAN}

Berdasarkan data penelitian yang telah diperoleh, dapat disimpulkan bahwa rata-rata hasil belajar siswa setelah menggunakan media kartu biologi berbahasa indonesia-mandarin secara keseluruhan adalah 76.29 dengan kategori baik. Pada konsep bakteri memperoleh rata-rata sebesar 40.7, jaringan pada manusia sebesar 94.45 , organ dan fungsi organ pada manusia sebesar 81,48 , mekanisme sistem organ pada manusia sebesar 98.15, tumbuhan sebesar 61.73, hewan sebesar 90.75 , jamur 31.45 , dan materi protista sebesar 72.25 .

\section{UCAPAN TERIMAKASIH}

Terima kasih penulis ucapkan kepada FKIP Universitas Tanjungpura yang telah membiayai penelitian ini melalui dana PNBP tahun 2018. Kepada ketua program studi pendidikan biologi dan pendidikan bahasa mandarin di FKIP Universitas Tanjungpura beserta para mahasiswa yang terlibat. 
Kepada para dosen dan guru yang telah memvalidasi instrumen dalam penelitian ini, dan juga terima kasih kepada kepala SMP Bilingual Immanuel Pontianak dan guru bahasa mandarin di kelas VIII.

\section{DAFTAR PUSTAKA}

Amerudin, Ariyati, E., \& Mardiyaningsih, A.N. (2013). Deskripsi Kesulitan Belajar dan Faktor Penyebabnya Pada Materi Fungi Di SMA Islam Bawari Pontianak dan Upaya Perbaikannya.

Retrieved from jurnal.untan.ac.id/index.php/jpdpb/article/viewFil $e / 3265 / p d f$.

Ariadi, S. (2017). Edugame Pengenalan BagianBagian Tubuh Manusia Dengan Tiga Bahasa Berbasisi Android. Surakarta: Universitas Muhammadiyah Surakarta.

Arsyad, A. (2011). Media Pembelajaran. Jakarta, Indonesia: PT. Raja Grafindo Persada.

Aqib, Z., dkk. (2009). Penelitian Tindakan Kelas. Bandung, Indonesia: CV. Yrama Widya.

Barrass, R. (1984). Some Misconseptions and Misunderstandings Perpetuated by Teachers and Textbooks of Biology. Journal of Biological Education, 18 (3). 201 - 206.

Bonwell, C., \& Eison, J. (1991). Active Learnin: Creating Excitement in The Classroom (ASHEERIC Higher Education Report No.1). Washington DC: George Washington University Press.

Fajriyah, U.N., \& Churiyah, M. (2016). Utilizing Instructional Media For Teaching Infrastructure Administration. Journal of Education and Practice 7 (6). 100 - 111.

Hanafiah, N \& Suhana, C. (2012). Konsep Strategi Pembelajaran. Bandung, Indonesia: Refika Aditama.

Hermaya, Miladiansyah, \& Angreni (tanpa tahun). Rancang Bangun Game Edukasi Pengenalan Taksonomi Hewan Mamalia Vertebrata Menggunakan Unity 3D. Retrieved from eprints.mdp.ac.id/1778/

Hidayatussaadah, R., Hidayati, S., \& Umniyatie, S. (2016). Identifikasi Kesulitan Belajar Siswa pada Materi Archaebacteria dan Eubacteria Di SMA Negeri 1 Muntilan. Jurnal Pendidikan Biologi, 5 (7). $58-69$.

Juni, M.H., \& Afiah, N. (2014). Research Design. International Jornal of Public Health and Clinical Sciences, 1 (2). 153 - 162.
Kemendikbud. (2013). Kerangka Dasar Kurikulum 2013. Jakarta, Indonesia: Kementerian Pendidikan dan Kebudayaan Direktorat Jenderal Pendidikan Dasar.

Khodijah, N. (2014). Psikologi Pendidikan. Jakarta, Indonesia: Rajawali Press.

Klees, G. \& Piepenbring, M. (2017). Animated Life Cycles of Fungi and Plants With Spores For Teaching. Journal of Biological Education, 52 (2), $130-142$.

Klemm, E.B., \& Tuthill, G. (2003). Best Practices. International Instructional Media, 30 (2), 177 193.

Makmun, A. S. (2004). Psikologi Kependidikan: Perangkat Sistem Pengajaran Modul. Bandung, Indonesia: PT. Remaja Rosdakarya.

Mulyati. (2005). Psikologi Belajar. Yogyakarta, Indonesia: ANDI.

Purwanto. (2008). Metodologi Penelitian Kuantitatif. Yogyakarta, Indonesia: Pustaka Pelajar.

Rahmatin, R \& Khabibah, S. (2016). Pengembangan Media Permainan Kartu Umath (Uno Mathemathics) Dalam Pembelajaran Matematika Pada Materi Pokok Operasi Bilangan Bulat. Mathedunesa Jurnal Ilmiah Pendidikan Matematika, 1 (5).

Susilana, R. \& Riyana, C. (2008). Media Pembelajaran. Bandung, Indonesia: CV. Wacana Prima.

Syaefudin, U. \& Syamsudin,A. (2007). Perencanaan Pendidikan. Bandung, Indonesia: PT. Remaja Rosdakarya.

Wilson, K.B. (2014). Impact of Emerging Technologies on Teacher Education: Experiences of Teacher - Trainees, Journal of Education and Practice. 5 (28). 168 - 175.

Zaenal, A. (2003). Media dan Sumber-sumber Belajar. Surakarta, Indonesia: UMS.

Zarisma, U., Qurbaniah, M., \& Muldayanti, N.D. (2016). Identifikasi Kesulitan Belajar Siswa Pada Materi DuniaTumbuhan Kelas X SMA Negeri Sambas. Retrieved from repository.unmuhpnk.ac.id/280/1/JURNAL\%20 UMI\%20ZARISMA.pdf

Zunitasari, D., Hidayati, S., \& Triatmanto. (2016). Identifikasi Kesulitan Belajar Protista Pada Siswa Kelas X Semester I SMA Negeri 1 Muntilan Tahun Ajaran 2015/2016. Jurnal Pendidikan Biologi, 5 (6). 17 - 27. 